\title{
TEORI ALJABAR AL-KHAWARIZMI
}

\author{
Riana Afliha Eka Kurnia \\ UIN Maulana Malik Ibrahim Malang \\ Email:afliha.21@gmail.com
}

\begin{abstract}
Abstrak
Islam generates leaders and scientists who influence and contribute greatly to the development of science. One of them is Al-Khwarizmi who is known as a scientist in the field of mathematics. He also produced many other works in the scientific world. Field of education has demonstrated that al-Khwarizmi was a prominent Islamic scientist. His knowledge and expertise not only in the field of Shari'ah but also in the fields of philosophy, logic, arithmetic,geometry, music, arithmetic, Islamic history and chemistry. His work is very fonumental and it's very well known, namely calculation and algebra. His prominent role in arithmatics of which he gave the cornerstone in mathematics combining arithmatichs and algebra forms and he introduced hindu's numerical system to Europe. For his work, he is well known in moslem and westen works of knowledge. He is named as the Father of Algebra.

Islam banyak melahirkan tokoh-tokoh dan ilmuwan yang memberi pengaruh dan kontribusi besar bagi perkembangan ilmu pengetahuan. Salah satunya adalah Al-Khawarizmi dikenal sebagai ilmuwan di bidang matematika. Beliau juga banyak menghasilkan karya-karya lain dalam dunia ilmu pengetahuan. Dalam pendidikan telah dibuktikan bahwa al-Khawarizmi adalah seorang tokoh Islam yang berpengetahuan luas. Pengetahuan dan keahliannya bukan hanya dalam bidang syari'at tapi di dalam bidang Falsafah, Logika, Aritmatika, Geometri, Musik, Ilmu Hitung, Sejarah Islam dan Kimia. Karyanya yang sangat fonumental dan sangat terkenal,di bidang matematika, yaitu mengenai perhitungan dan Aljabar. Kiprah Al-Khawarizmi yang paling menonjol memang dalam bidang Aritmatika, yaitu memberi dasar dan tonggak dalam matematika, menggabungkan bentuk-bentuk Aritmatika dan Aljabar, serta mengenalkan bilangan-bilangan Hindu ke benua Eropa. Atas jasanya itu beliau hingga sekarang sangat dikenal, baik di dunia ilmu pengetahuan Islam dan Barat. Atas karyanya di bidang Matematika tersebut beliau akhirnya di beri gelar Bapak Aljabar.
\end{abstract}

Kata Kunci: Islam, Ilmuwan,Al-Khawarizmi, Matematika

Muhammad bin Musa al-Khawarizmi, adalah ahli Matematika, Astronomi, Astrologi, dan Geografi yang berasal dari Persia. Lahir sekitar tahun 780 di Khawarizm (sekarang Khiva, Uzbekistan). Hampir sepanjang hidupnya, ia bekerja sebagai dosen di Sekolah Kehormatan di Baghdad. ${ }^{1}$ Nama Asli dari al-Khawarizmi ialah Muhammad Ibn Musa alKhawarizmi. Selain itu beliau dikenali sebagai Abu Abdullah Muhammad bin Ahmad bin Yusoff. AlKhawarizmi dikenal di Barat sebagai al-Khawarizmi, al-Cowarizmi, al-Ahawizmi, al-Karismi, al-Goritmi, al-Gorismi. ${ }^{2}$

Kepribadian al-Khawarizmi telah diakui oleh orang Islam maupun di dunia Barat. Hal ini dibuktikan dengan adanya seorang ilmuwan Barat, yaitu G.Sarton

\footnotetext{
http://id.wikipedia.org

2 http://id.wikipedia.org.
}

mengatakan bahwa "pencapaian-pencapaian yang tertinggi telah diperoleh oleh orang-orang Timur...." Sementara tokoh lain, Wiedmann berkat "...al-Khawarizmi mempunyai kepribadian yang teguh dan seorang yang mengabdikan hidupnya untuk dunia sains". 3

Kepandaian dan kecerdasannya mengantarkannya masuk ke lingkungan Dar al-Hukama (Rumah Kebijaksanaan), sebuah lembaga penelitian dan pengembangan ilmu pengetahuan yang didirikan oleh Ma'mun Ar-Rasyid, seorang khalifah Abbasiyah yang terkenal. Riwayat Al-Khawarizmi sendiri sebenarnya tidak banyak diketahui oleh orang banyak, termasuk para

http://abihafiz.wordpress.com/2008/05/02/al-khawarizmi-bapakilmu-aljabar-aritmetika-dan-astronomi-2/http://abihafiz.wordpress. com/2008/05/02/al-khawarizmi-bapak-ilmu-aljabar-aritmetika-danastronomi-2/ 
ahli sejarah. Dari namanya banyak ahli yang mengindikasikan bahwa beliau berasal dari daerah Khawarizm, sebuah daerah yang terletak di sebelah selatan Laut Aral di sekitar Asia Tengah. Namun, seorang tokoh sejarah bernama al-Tabari, juga pernah menjuluki beliau sebagai al-Qutrubulli, yang berarti beliau berasal dari Qutrubul sebuah daerah yang berada di antara sungai Tigris dan Eufrat di Baghdad Irak.

Beliau diperkirakan hidup di zaman pemerintahan emas tiga raja Dinasti Abbasiyah yang terkenal, yaitu Al-Mansur, Harun Al-Rasyid dan Al-Ma'mun. Namun, diketahuibahwabeliaupernahbekerjapadamasa Dinasti Al-Ma'mun, tepatnya di Graha Kebijaksanaan (The House of Wisdom). Di tempat ini beliau ditugaskan untuk menerjemahkan karya-karya ilmiah yang berasal dari para filsuf Yunani, seperti karya-karya Aristoteles dan Ptolemeus ${ }^{4}$. Al-Khawarizmi wafat antara tahun 220 dan 230M. Ada yang mengatakan al-Khawarizmi hidup sekitar awal pertengahan abad ke-9 M. Sumber lain menegaskan beliau hidup di Khawarism, Usbekistan pada tahun 194H/780M dan meninggal tahun 266H/850M di Baghdad. nulis: ${ }^{5}$

Tentang agama al-Khawarizmi, Toomer me-

Sebutan lain untuk beliau diberikan oleh alTabarî, "al-Majusi," ini mengindikasikan ia adalah pengikut Zoroaster.Ini mungkin terjadi pada orang yang berasal dari Iran. Tetapi, kemudian buku AlJabar beliau menunujukkan beliau adalah seorang Muslim Ortodok, jadi sebutan Al-Tabari ditujukan pada saat ia muda, ia beragama Majusi.

Dalam Kitab al-Fihrist, karya Ibnu al-Nadim, dapat kita temukan sejarah singkat beliau, bersama dengan karya-karya tulis beliau. Al-Khawarizmi menekuni hampir seluruh pekerjaannya antara 813833 M. setelah Islam masuk ke Persia, Baghdad menjadi pusat ilmu dan perdagangan, dan banyak pedagang dan ilmuwan dari Cina dan India berkelana ke kota ini, yang juga dilakukan beliau. Dia bekerja di Baghdad pada Sekolah Kehormatan yang didirikan oleh Khalifah Bani Abbasiyah Al-Ma'mun, tempat ia belajar Ilmu Alam dan Matematika, termasuk mempelajari terjemahan manuskrip Sanskerta dan Yunani. ${ }^{6}$

4 Ade Firmansyah, 108 Ilmuwan dan Penemu Dunia, (Jogjakarta: Ar Ruzz Media, 2009), 11.

5 http://risalahrasul.wordpress.com/2008/06/02/al-khawarizmi-780-846-mmatematikawan-muslim/.

6 http://hafez.wordpress.com/2008/03/14/seri-biografi-tokoh-islam-alkhawarizmi/

\section{Peranan Dan Sumbangan Al-Khawarizmi}

Dalam pendidikan telah dibuktikan bahwa alKhawarizmi adalah seorang tokoh Islam yang berpengetahuan luas. Pengetahuan dan keahliannya bukan hanya dalam bidang syariat tapi di dalam bidang Falsafah, Logika, Aritmatika, Geometri, Musik, Ilmu Hitung, Sejarah Islam dan Kimia.

Al-Khawarizmi sebagai guru Aljabar di Eropa telah menciptakan pemakaian Secans dan Tangen dalam penyelidikan Trigonometri dan Astronomi. Dalam usia muda beliau bekerja di bawah pemerintahan Khalifah al-Ma'mun, bekerja di Bayt alHikmah di Baghdad. Beliau bekerja dalam sebuah observatory yaitu tempat belajar Matematika dan Astronomi. Al-Khawarizmi juga dipercaya untuk memimpin perpustakaan khalifah. Beliau pernah memperkenalkan angka-angka India (Hindu) dan caracara perhitungan India pada dunia Islam. Beliau juga merupakan seorang penulis Ensiklopedia. Al-Khawarizmi adalah seorang tokoh yang pertama kali memperkenalkan aljabar dan hisab (perhitungan). Banyak lagi ilmu pengetahuan yang beliau pelajari dalam bidang matematika dan menghasilkan konsep-konsep Matematika yang begitu populer yang masih digunakan sampai sekarang ${ }^{7}$.

Beberapa cabang ilmu dalam Matematika yang diperkenalkan oleh al-Khawarizmi seperti: Geometri, Aljabar, Aritmatika dan lain-lain. Geometri merupakan cabang kedua dalam Matematika. Isi kandungan yang diperbincangkan dalam cabang kedua ini ialah asalusul geometri dan rujukan utamanya ialah Kitab alUstugusat (The Element) hasil karya Euclid. Geometri dari segi bahasa berasal dari pada perkataan Yunani yaitu 'geo' yang berarti bumi dan 'metri' berarti pengukuran. Dari segi ilmu, Geometri adalah ilmu yang mengkaji hal yang berhubungan dengan magnitud dan sifat-sifat ruang. Geometri ini dipelajari sejak zaman Fir'aun (2000SM). Kemudian Thales Miletus memperkenalkan geometri Mesir kepada Yunani sebagai satu sains dalam kurun abad ke 6 SM. Seterusnya sarjana Islam telah menyempurnakan kaidah pendidikan sains ini terutama pada abad ke9M. ${ }^{8}$

Algebra/Aljabar merupakan nadi Matematika. Karya Al-Khawarizmi telah diterjemahkan oleh Gerhard of Gremano dan Robert of Chaster ke dalam bahasa Eropa pada abad ke-12. Sebelum munculnya

\footnotetext{
7 http://abihafiz.wordpress.com/2008/05/02/al-khawarizmi-bapakilmu-aljabar-aritmetika-dan-astronomi-2/http://abihafiz.wordpress. com/2008/05/02/al-khawarizmi-bapak-ilmu-aljabar-aritmetika-danastronomi-2/

8 Khalid Haddad, 12 Tokoh Pengubah Dunia, (Jakarta, Depok: Gema Insani, 2009),216.
} 
karya yang berjudul 'Hisab al-Jibra wa al Muqabalah yang ditulis oleh al-Khawarizmi pada tahun $820 \mathrm{M}$. Sebelum ini tak ada istilah aljabar. Al-Khawarizmi dalam ilmu ukur sudut juga luar biasa. Tabel ilmu ukur sudutnya yang berhubungan dengan fungsi sinus dan garis singgung tangen telah membantu para ahli Eropa memahami lebih jauh tentang ilmu ini'.

Selain Matematika, Al-Khawarizmi juga dikenal sebagai astronom. Di bawah Khalifah Ma'mun, sebuah tim astronom yang dipimpinnya berhasil menentukan ukuran dan bentuk bundaran bumi. Penelitian ini dilakukan di Sanjar dan Palmyra. Hasilnya hanya selisih 2,877 kaki dari ukuran garis tengah bumi yang sebenarnya. Sebuah perhitungan luar biasa yang dapat dilakukan pada saat itu. AlKhawarizmi juga menyusun buku tentang penghitungan waktu berdasarkan bayang-bayang matahari. Al-Khawarizmi juga seorang ahli Geografi. Bukunya, Surat al-Ardl (Bentuk Rupa Bumi), menjadi dasar geografi Arab. Karya tersebut masih tersimpan di Strassberg, Jerman ${ }^{10}$.

Selain ahli di bidang Matematika, Astronomi, dan Geografi, Al-Khawarizmi juga seorang ahli seni musik. Dalam salah satu buku matematikanya, AlKhawarizmi menuliskan pula teori seni musik. Pengaruh buku ini sampai Eropa dan dianggap sebagai perkenalan musik Arab ke dunia Latin. Dengan meninggalkan karya-karya besarnya sebagai ilmuwan terkemuka dan terbesar pada zamannya, Al-Khawarizmi meninggal pada tahun $262 \mathrm{H} / 846 \mathrm{M}$ di Bagdad.

Al-Khawarizmi adalah salah seorang ilmuwan Timur Tengah yang sangat populer. Beliau terkenal berkat karyanya: Hisab al-Jabr wal Muqbala, yaitu sebuah karya di bidang Matematika yang memaparkan cara termudah dan paling bermanfaat dari bentuk Aritmatika. Di dalam karyanya tersebut, beliau juga memaparkan mengenai dasar-dasar penggunaan alJabar dan sekaligus mempopulerkan istilah tersebut yang sekarang berubah menjadi Aljabar.

Al-Khawarizmi banyak menghasilkan karya ilmiah. Karya-karya yang dihasilkan Al-Khawarizmi selain di bidang Aritmatika, adalah Shindind Zij yaitu sebuah buku tentang Astronomi. Buku ini memuat rumusan pembuatan kalender, menghitung posisi matahari, bulan dan planet-planet, memuat tabel sinus dan tangen, tabel astrologi dan perkiraan terjadinya gerhana matahari dan gerhana bulan.

\footnotetext{
9 http://risalahrasul.wordpress.com/2008/06/02/al-khawarizmi-780-846-mmatematikawan-muslim/

10 http://abihafiz.wordpress.com/2008/05/02/al-khawarizmi-bapak-ilmualjabar-aritmetika-dan-astronomi
}

Sementara itu, di bidang geologi, Al-Khawarizmi juga berhasil menentukan garis lintang dan garis bujur di 2402 tempat berdasarkan peta dunia. Hal ini mirip dengan yang ada di dalam karya Ptomeleus. Namun pada karya al-Khawarizmi terdapat beberapa tempat yang digambarkan secara lebih rinci lagi, yakni garis lintang dan garis bujur untuk wilayah taklukan Islam, Afrika dan Timur Jauh, sementara untuk wilayah Eropa Al-Khawarizmi mengadaptasinya dari karya Ptomeleus. ${ }^{11}$ Masih dalam bidang Geologi, Al-Khawarizmi juga menulis topik tentang penggunaan Astrolabe, yaitu suatu pengukur lintasan planet sebelum ditemukannya sekstansextant, untuk mengetahui lintasan matahari dan mempelajari kalender Yahudi ${ }^{12}$.

Karya Al-Khawarizmi dalam bidang ilmu pengetahuan sangat banyak. Hal ini karena beliau adalah salah satu tokoh ilmuwan Islam yang sangat diakui kejeniusannya. Selain itu pada masanya beliau juga didukung oleh Dinasti Al-Ma'mun yang sangat mencintai ilmu-ilmu pengetahuan. Al-Ma'mun pada masa itu memerintahkan para ilmuwan-ilmuwan andalan Timur Tengah untuk mempelajari karya-karya ilmuwan lain dan menghasilkan karya di bidang ilmu pengetahuan untuk kemajuan kerajaan Islam $^{13}$.

Kiprah Al-Khawarizmi yang paling menonjol memang dalam bidang Aritmatika, yaitu memberi dasar dan tonggak dalam Matematika, menggabungkan bentuk-bentuk Aritmatika dan Aljabar serta mengenalkan bilangan-bilangan Hindu ke benua Eropa. Atas jasa-jasanya itulah beliau hingga sekarang sangat dikenal, baik di dunia ilmu pengetahuan Islam dan Barat. Atas karyanya yang populer tersebut, oleh dunia ilmu pengetahuan, beliau akhirnya di beri gelar "Bapak Aljabar". Buku pertamanya, al-Jabar, adalah buku pertama yang membahas solusi sistematik dari linear dan notasi kuadrat. Sehingga ia disebut sebagai Bapak Aljabar. Selain itu, beliau juga melakukan translasi bahasa Latin dari Aritmatika beliau yang di dalamnya berisi tentang memperkenalkan angka India, yang kemudian diperkenalkan sebagai Sistem Penomoran Posisi Desimal di dunia Barat pada abad ke 12. Ia merevisi dan menyesuaikan Geografi Ptolemeus sebaik mengerjakan tulisan-tulisan tentang Astronomi dan Astrologi.

Kontribusi beliau tak hanya berdampak besar pada Matematika, tapi juga dalam kebahasaan. Kata Aljabar berasal dari kata al-Jabr, satu dari dua operasi

\footnotetext{
11 Adhe Firmansyah,Op.Cit

12 Ibid..

13 Khalid Haddad, Op.Cit
} 
dalam Matematika untuk menyelesaikan notasi kuadrat, yang tercantum dalam buku beliau. Kata logarisme dan logaritma diambil dari kata Algorismi, latinisasi dari nama beliau. Nama beliau juga di serap dalam bahasa Spanyol Guarismo dan dalam bahasa Portugis, Algarismo yang berarti digit.

Karya terbesar beliau dalam matematika, astronomi, astrologi, geografi, kartografi, sebagai fondasi dan kemudian lebih inovatif dalam aljabar, trigonometri, dan pada bidang lain yang beliau tekuni. Pendekatan logika dan sistematis beliau dalam penyelesaian linear dan notasi kuadrat memberikan keakuratan dalam disiplin aljabar, nama yang diambil dari nama salah satu buku beliau pada tahun 830 M, al-Kitab al-mukhtasar fi hisab al-jabr wa'l-muqabalaatau: "Buku Rangkuman untuk Kalkulasi dengan Melengkapakan dan Menyeimbangkan", buku pertama beliau yang kemudian diterjemahkan ke dalam bahasa Latin pada abad ke-12. ${ }^{14}$

Padabuku beliau, Kalkulasi dengan angka Hindu, yang ditulis tahun 825 , memprinsipkan kemampuan difusi angka India ke dalam perangkaan timur tengah dan kemudian Eropa. Buku beliau diterjemahkan ke dalam bahasa Latin, Algoritmi de numero Indorum, menunjukkan kata Algoritmi menjadi bahasa Latin. Beberapa kontribusi beliau berdasar pada Astronomi Persia dan Babilonia, angka India, dan sumbersumber Yunani.

Sistemasi dan koreksi beliau terhadap data Ptolemeus pada geografi adalah sebuah penghargaan untuk Afrika dan Timur -Tengah. Buku besar beliau yang lain, Kitab surat al-Ardl ("Pemandangan Bumi”; diterjemahkan oleh Geography), yang memperlihatkan koordinat dan lokasi dasar yang diketahui dunia dengan berani mengevaluasi nilai panjang dari Laut Mediterania dan lokasi kota-kota di Asia dan Afrika yang sebelumnya diberikan oleh Ptolemeus. Ia kemudian mengepalai konstruksi peta dunia untuk Khalifah Al-Ma'mun dan berpartisipasi dalam proyek menentukan tata letak di Bumi, bersama dengan 70 ahli geografi lain untuk membuat peta yang kemudian disebut "Ketahuilah Dunia". Ketika hasil kerjanya disalin dan ditransfer ke Eropa dan Bahasa Latin, menimbulkan dampak yang hebat pada kemajuan matematika dasar di Eropa. Ia juga menulis tentang Astrolab dan Sundial.

Karya Aljabarnya yang paling monumental berjudul al-Mukhtasar fi Hisab al-Jabr wal-Muqabalah (Ringkasan Perhitungan Aljabar dan Perbandingan)

14 Khalid Haddad, Ibid
Dalam buku ini diuraikan pengertian-pengertian geometris. Ia juga menyumbangkan teorema segitiga sama kaki yang tepat, perhitungan tinggi serta luas segitiga, dan luas jajar genjang serta lingkaran. Dengan demikian, dalam beberapa hal al-Khawarizmi telah membuat aljabar menjadi ilmu eksak. Buku ini diterjemahkan di London pada tahun 1831 oleh F. Rosen seorang matematikawan Inggris, kemudian diedit ke dalam bahasa Arab oleh Ali Mustafa Musyarrafa dan Muhammad Mursi Ahmad, ahli Matematika Mesir, pada tahun 1939. Sebagian dari karya al-Khawarizmi ini pada abad ke-12 juga diterjemahkan oleh Robert, matematikawan dari Chester, Inggris, dengan judul Liber Algebras et Al-mucabola (Buku Aljabar dan Perbandingan), yang kemudian diedit oleh L.C. Karpinski, seorang Matematikawan dari New York, Amerika Serikat. Gerard dari Cremona (1114-1187) seorang Matematikawan Italia, membuat versi kedua dari buku Liber Algebras di atas dengan judul De Jebra et Almucabola (Aljabar dan Perbandingan). Buku versi Gerard ini lebih baik dan bahkan mengungguli buku F. Rozen.

Dalam bukunya al-Khawarizmi memperkenalkan kepada dunia ilmu pengetahuan angka 0 (nol) yang dalam bahasa arab disebut sifr. Sebelum al-Khawarizmi memperkenalkan angka nol, para ilmuwan mempergunakan abakus, semacam daftar yang menunjukkan satuan, puluhan, ratusan, ribuan, dan seterusnya, untuk menjaga agar setiap angka tidak saling tertukar dari tempat yang telah ditentukan dalam hitungan. Akan tetapi, hitungan seperti ini tidak mendapat sambutan dari kalangan ilmuwan Barat ketika itu dan mereka lebih tertarik untuk mempergunakan raqam al-binji (daftar angka arab, termasuk angka nol), hasil penemuan al-khawarizmi. Dengan demikian angka nol baru dikenal dan dipergunakan orang Barat sekitar 250 tahun setelah ditemukan al-Khawarizmi ${ }^{15}$.

Dari beberapa bukunya al-Khawarizmi mewariskan beberapa istilah Matematika yang masih banyak dipergunakan hingga kini, seperti sinus, kosinus, tangen dan kotangen. Karya-karya al-Khawarizmi di bidang Matematika sebenarnya banyak mengacu pada tulisan mengenai aljabaryang disusun oleh Diophantus (250 SM) dari Yunani. Namun, dalam meneliti bukubuku aljabar tersebut al-Khawarizmi menemukan beberapa kesalahan dan permasalahan yang masih kabur. Kesalahan dan permasalahan ini diperbaiki, dijelaskan, dan dikembangkan oleh al-Khawarizmi

15 Muhammad Gharib Jaudah, 147 Ilmuwan Terkemuka Dalam Sejarah Islam, (Jakarta: Pustaka Al-Kautsar, 2007), 101. 
dalam karya-karya aljabarnya. Oleh sebab itu, tidaklah mengherankan apabila ia dijuluki "Bapak Aljabar". Bahkan menurut Gandz, Matematikawan Barat dalam bukunya The Source of al-Khawarizmi's Algebra, alKhawarizmi lebih berhak mendapat julukan "Bapak Aljabar" dibandingkan dengan Diophantus karena dialah orang pertama yang mengajarkan aljabar dalam bentuk elementer serta menerapkannya dalam hal-hal yang berkaitan dengannya. Di bidang ilmu ukur, alKhawarizmi juga dikenal sebagai peletak rumus ilmu ukur dan penyusun daftar logaritma serta hitungan desimal. Namun beberapa sarjana Matematika Barat, seperti John Napier (1550-1617) dan Simon Stevin (1548-1620), menganggap penemuan di atas merupakan hasil pemikiran mereka ${ }^{16}$.

\section{Karya}

Sumbangsihnya dalam bentuk hasil karya diantaranya ialah : Al-Jabr wa'l Muqabalah karena beliau telah mencipta pemakaian secans dan tangens dalam penyelidikan trigonometri dan astronomi; Hisab al-Jabr wa al-Muqabalah: Beliau telah mengajukan contoh-contoh persoalan matematika dan mengemukakan 800 buah masalah yang sebagian besar merupakan persoalan yang dikemukakan oleh Neo, Babylian dalam bentuk dugaan yang telah dibuktikan kebenarannya oleh al-Khawarizmi; Sistem Nomor : Beliau telah memperkenalkan konsep sifat dan ia penting dalam sistem Nomor pada zaman sekarang. Karyanya yang satu ini memuat Cos, Sin dan Tan dalam penyelesaian persamaan trigonometri , teorema segitiga sama kaki dan perhitungan luas segitiga, segi empat dan lingkaran dalam geometri.

Banyak lagi konsep dalam matematika yang telah diperkenalkan al-Khawarizmi. Bidang astronomi juga membuat al-Khawarizmi terkenal. Astronomi dapat diartikan sebagai ilmu falaq (pengetahuan tentang bintang-bintang yang melibatkan kajian tentang kedudukan, pergerakan, dan pemikiran serta tafsiran yang berkaitan dengan bintang).

Karya lainnya Hisab al-Jabr wa al-Muqabla (Pengutuhan Kembali dan Pembandingan) dan AlJama' wa at-Tafriq bi Hisab al-Hind (Menambah dan Mengurangi dalam Matematika Hindu) adalah dua di antara karya-karya Al-Khawarizmi dalam bidang Matematika yang sangat penting. Kedua karya tersebut banyak menguraikan tentang persamaan linier dan kuadrat; penghitungan integrasi dan persamaan dengan 800 contoh yang berbeda; tanda-tanda negatif yang se-

16 http://kolom-biografi.blogspot.com/2009/01/biografi-al-khawarizmi.html belumnya belum dikenal oleh bangsa Arab. Dalam AlJama' wa at-Tafriq, Al-Khawarizmi menjelaskan tentang seluk-beluk kegunaan angka-angka, termasuk angka nol dalam kehidupan sehari-hari. Karya tersebut juga diterjemahkan ke dalam bahasa Latin. Al-Khawarizmi juga diyakini sebagai penemu angka nol. ${ }^{17}$

Jika karya-karya Al-Khawarizmi di klasifikasikan maka kita bisa melihat beberapa diantaranya seperti ${ }^{18}$ : Buku I - Aljabar: Sebuah halaman dari Aljabar al-Khawarizma, Al-Kitab Al-Mukhtașar Fi Hisab Al-Jabr Wa-L-Muqabala (Buku Rangkuman Kalkulasi dengan Melengkapkan dan Menyeimbangkan) adalah buku Matematika yang ditulis tahun 830 . Buku tersebut merangkum definisi Aljabar. Buku ini diterjemahkan ke dalam Bahasa Latin berjudul Liber algebrae et almucabala oleh Robert of Chester (Segovia, 1145) dan juga oleh Gerard of Cremona. Metode beliau dalam menyelesaikan linear dan notasi kuadrat dilakukan dengan meredusi notasi ke dalam 6 bentuk standar (dimana $\mathrm{b}$ dan $\mathrm{c}$ adalah angka positif): Angka ekual kuadrat $\left(a x^{2}=c\right)$, Angka ekual akar ( $b x$ $=c$ ), Kuadrat dan akar ekual $\left(a x^{2}+b x=c\right)$, Kuadrat dan angka akar ekual $\left(a x^{2}+c=b x\right)$, Akar dan angka kuadrat ekual $\left(b x+c=a x^{2}\right)$, Kuadrat ekual akar $\left(a x^{2}\right.$ $=b x) .{ }^{19}$ Dengan membagi koefisien dari kuadrat dan menggunakan dua operasi aljabar (penyimpanan atau melengkapkan) dan al-muqābala (menyeimbangkan). Aljabar adalah proses memindahkan unit negatif, akar dan kuadrat dari notasi dengan menggunakan nilai yang sama di kedua sisi. Contohnya, $x^{2}=40 x-$ $4 x^{2}$ disederhanakan menjadi $5 x^{2}=40 x$.

Al-muqabala adalah proses memberikan kuantitas dari tipe yang sama ke sisi notasi. Contohnya, $x^{2}+14=x+5$ disederhanakan ke $x^{2}+9=x$. Beberapa pengarang telah menerbitkan tulisan dengan nama Kitab al-Gabr wal-Muqabala, termasuk Abu Ḥanifa al-Dinawari, Abu Kamil (Rasala fi al-gabr wa-almuqabala), Ibnu Turk, Sind bin 'Alī, Sahl bin Bisr, dan Sarafaddin al-Ṭusi.

Buku kedua besar beliau adalah tentang Aritmatika, yang bertahan dalam Bahasa Latin, tapi hilang dari Bahasa Arab yang aslinya. Translasi dilakukan pada abad ke-12 oleh Adelard of Bath, yang juga menerjemahkan tabel Astronomi pada 1126. Pada manuskripnya yang berbahasa Latin, biasanya tak bernama, tetapi umumnya dimulai dengan kata: Dixit algorizmi ("Seperti kata al-Khawârizmî"), atau Algoritmi de numero Indorum ("al-Kahwârizmî pada

\footnotetext{
17 http://kolom-biografi.blogspot.com/2009/01/biografi-al-khawarizmi.html

18 http://id.wikipedia.org/

19 Muhammad Gharib Jaudah, Op.Cit.
} 
angka kesenian Hindu"), sebuah nama baru diberikan pada hasil kerja beliau oleh Baldassarre Boncompagni pada 1857 . Kitab aslinya diperkirakan bernama alJam'a wal-tafriq bi-hisab al-Hind(“Buku Penjumlahan dan Pengurangan berdasarkan Kalkulasi Hindu”).

Buku Zïj al-Sindhind("tabel astronomi") adalah buku keempat, karya yang terdiri dari 37 simbol pada kalkulasi kalender Astronomi dan 116 tabel dengan kalenderial, Astronomial dan data Astrologial sebaik data yang diakui sekarang. Versi aslinya dalam Bahasa Arab (ditulis 820) hilang, tapi versi lain oleh astronomer Spanyol Maslama al-Majriti (1000) tetap bertahan dalam bahasa Latin, yang diterjemahkan oleh Adelard of Bath (26 Januari 1126). Empat manuskrip lainnya dalam bahasa Latin tetap ada di Bibliothčque publique (Chartres), the Bibliothčque Mazarine (Paris), the Bibliotheca Nacional (Madrid) dan the Bodleian Library (Oxford). ${ }^{20}$

Al-Khawarizmi juga menulis tentang Penanggalan Yahudi (Risala fi istikhraj ta'rikh alyahud"Petunjuk Penanggalan Yahudi"). Yang menerangkan 19 tahun siklus interkalasi, hukum yang mengatur pada hari apa dari suatu minggu bulan Tishri dimulai; memperhitungkan interval antara Era Yahudi(penciptaan Adam) dan era Seleucid ; dan memberikan hukum tentang bujur matahari dan bulan menggunakan Kalender Yahudi. Sama dengan yang ditemukan oleh al-Biruini dan Maimonides.

Beberapa manuskrip Arab di Berlin, Istanbul, Tashkent, Kairo dan Paris berisi pendekatan material yang berkemungkinan berasal dari al-Khawarizmi. Manuskrip di Istanbul berisi tentang sundia, yang di-

20 http://risalahrasul.wordpress.com/2008/06/02/al-khawarizmi-780-846-mmatematikawan-muslim/

\section{Daftar Pustaka}

\section{Buku}

Firmansyah, Ade, 108 Ilmuwan dan Penemu Dunia, (Jogjakarta: Ar Ruzz Media, 2009).

Haddad, Khalid, 12 Tokoh Pengubah Dunia, (Jakarta, Depok: Gema Insani, 2009).

Jaudah, Muhammad Gharib, 147 Ilmuwan Terkemuka Dalam Sejarah Islam, (Jakarta: Pustaka AlKautsar, 2007.

\section{Website}

http://id.wikipedia.org.

http://kolom-biografi.blogspot.com/2009/01/ sebut dalam Fihirst. Karya lain, seperti determinasi arah Mekkah adalah salah satu astronomi sferik. Dua karya berisi tentang pagi (Ma'rifat sa'at al-mashriq fi kull balad) dan determinasi azimut dari tinggi (Ma'rifat al-samt min qibal al-irtifá'). Beliau juga menulis 2 buku tentang penggunaan dan perakitan astrolab. Ibnu al-Nadim dalam Kitab al-Fihrist (sebuah indeks dari bahasa Arab) juga menyebutkan Kitab ar-Rukama (buku sundial) dan Kitab al-Tarikh (buku sejarah). Tapi 2 yang terakhir disebut telah hilang ${ }^{21}$.

\section{Kesimpulan}

Al-Khawarizmi adalah tokoh ilmuwan pertama yang menulis buku dalam bidang Matematika, dan penjelasannya menggunakan huruf-huruf India, serta sistem kuadrat, pecahan dan akar. Dia juga orang pertama yang menyadarai akan pentingnya nilai kosong dalam penomoran dan hitungan.

Al-Khawarizmi telah memberikan kontribusi yang besar dala, mendorong roda peradaban manusia hingga kita sekarang sampai pada fase peradaban dunia yang maju disebabkan oleh beberapa hasil penelitian ilmiah dan buku-buku yang dikarang di bidang Matematika (Menghitung, Aljabar dan Geometri). Selain itu beliau juga berkontribusi dalam bidang Astronomi, Geografi dan Musik.

Pada masanya beliau sendiri telah mendapatkan dua kepercayaan Khalifah sekaligus, sehingga keduanya menyerahkan tugas-tugas penting dalam bidang riset dan penelitian ilmiah kepada Al-Khawarizmi. Hingga saat ini, nama Al-Khawarizmi terus dikenal sebagai "Bapak Al-Jabar" di dunia ilmu pengetahuan berkat penemuannya yang fonumental tersebut.

21 http://risalahrasul.wordpress.com/2008/06/02/al-khawarizmi-780-846-mmatematikawan-muslim/

biografi-al-khawarizmi.html

http://hafez.wordpress.com/2008/03/14/seri-biografitokoh-islam-al-khawarizmi/

http://abihafiz.wordpress.com/2008/05/02/alkhawarizmi-bapak-ilmu-aljabar-aritmetikadan-astronomi-2/http://abihafiz.wordpress. com/2008/05/02/al-khawarizmi-bapak-ilmualjabar-aritmetika-dan-astronomi-2/

http://risalahrasul.wordpress.com/2008/06/02/ al-khawarizmi-780-846-m-matematikawanmuslim/ 